\title{
Efficacy and safety of MK-7243: a grass allergy sublingual immunotherapy tablet evaluated in Canadian adults and children
}

\author{
Jacques Hébert ${ }^{1 *}$, Michael Blaiss ${ }^{2}$, Susan Waserman ${ }^{3}$, Harold Kim$^{3}$, Peter Creticos ${ }^{4}$, Jennifer Maloney ${ }^{5}$, \\ Amarjot Kaur ${ }^{5}$, Harold S Nelson ${ }^{6}$, Hendrik Nolte ${ }^{5}$ \\ From Canadian Society of Allergy and Clinical Immunology Annual Scientific Meeting 2014 \\ Ottawa, ON, Canada. 23-26 October 2014
}

\section{Background}

The effect of MK-7243 (2800 BAU/75,000 SQ [ 15 $\mu \mathrm{g}$ of Phleum pratense $p$ 5], Merck/ALK-Abelló), a sublingual Timothy grass immunotherapy tablet, has been evaluated in several randomized, placebo-controlled, double-blind trials; three of these trials were conducted in adults and children in North America (the United States and Canada) who have allergic rhinitis with or without conjunctivitis (AR/C). We conducted a post-hoc analysis to investigate the effect of MK-7243 in Canadian subpopulations.

\section{Methods}

Data from Canadian subjects from the three trials were used in this investigation: P05238 (adults $\geq 18$ y; pollen season: 2009); P05239 (children $5-<18$ y; pollen season $=2009$ ); and P08067 (adults $\geq 65 \mathrm{y}$ and children $5-<18$ y; pollen season: 2012). Trial data from the same grass pollen seasons (GPS) were pooled. Subjects received once-daily MK-7243 or placebo starting $\geq 12 \mathrm{wk}$ before and continuing throughout the GPS, for a mean total of $\geq 23 \mathrm{wk}$. The therapeutic effect of MK-7243 was evaluated for rhinoconjunctivitis symptoms and symptomatic medication use, measured as a total combined score $(\mathrm{TCS}=$ daily-symptom score [DSS; $\max =18]+$ dailymedication score [DMS; $\max =36]$ ) averaged over the entire GPS. Safety was assessed by monitoring adverse events (AEs).

'Centre de Recherche Appliquée en Allergie de Québec, Québec City, QC, Canada

Full list of author information is available at the end of the article

\section{Results}

Canadian subjects taking MK-7243 $(\mathrm{n}=42)$ in the pooled adult-pediatric 2009 trials showed a 38\% mean TCS reduction versus placebo $(n=54 ;-2.06$ difference [95\% CI: $-3.72,-0.39$ ]; 3.32 vs. 5.37). Canadian subjects taking MK-7243 ( $\mathrm{n}=122)$ in the adult-pediatric 2012 trial showed a $33 \%$ mean TCS reduction relative to placebo $(\mathrm{n}=122 ;-1.62$ difference [95\% CI: $-2.54,-0.71]$; 3.34 vs. 4.96). Approximately $90 \%$ of treatment-related AEs were mild or moderate in severity. No serious or life-threatening treatment-related AEs occurred.

\section{Conclusions}

MK-7243 Timothy grass sublingual tablet significantly improved AR/C induced by Timothy grass pollen in Canadian adults and children 5 y and older. Similar efficacy and safety results were obtained for the overall populations of the three trials.

\section{Trial registration}

ClinicalTrials.gov Identifiers: NCT00562159; NCT00 550550; NCT01385371.

\section{Acknowledgements}

Medical writing and editorial assistance was provided by Erin P. Scott, PhD. This assistance was funded by Merck \& Co., Inc., Whitehouse Station, NJ, USA. Editorial assistance was also provided by Jorge Moreno-Cantu, PhD, Global Scientific and Medical Publications, Office of the Chief Medical Officer, Merck \& Co., Inc., Whitehouse Station, NJ, USA.

\section{Authors' details}

'Centre de Recherche Appliquée en Allergie de Québec, Québec City, QC, Canada. ${ }^{2}$ Departments of Medicine and Pediatrics, University of Tennessee Health Science Center, Memphis, TN, USA. ${ }^{3}$ Department of Medicine, McMaster University, Hamilton, ON, Canada. ${ }^{4}$ Department of Medicine, Johns Hopkins University School of Medicine, Baltimore, MD, USA. ${ }^{5}$ Merck \& Co., 
Published: 18 December 2014

doi:10.1186/1710-1492-10-S2-A16

Cite this article as: Hébert et al:: Efficacy and safety of MK-7243: a grass allergy sublingual immunotherapy tablet evaluated in Canadian adults and children. Allergy, Asthma and Clinical Immunology 2014 10(Suppl 2):

A16.

Submit your next manuscript to BioMed Central and take full advantage of:

- Convenient online submission

- Thorough peer review

- No space constraints or color figure charges

- Immediate publication on acceptance

- Inclusion in PubMed, CAS, Scopus and Google Scholar

- Research which is freely available for redistribution

Submit your manuscript at www.biomedcentral.com/submit 